\title{
Endorsement of the Consortium in the report, "Towards a Partnership for the 21st Century - The Enhanced and More Operational Partnership,” Appendix E, Improved Training and Education in the Partnership for Peace
}

\author{
Appendix E \\ Improving Training and Education \\ in Partnership for Peace
}

This Appendix develops an outline for a programme to improve and optimise training and education in the Partnership. It takes account of initial military advice.

\section{Outline Programme}

\section{Introduction}

1. The December 1998 Ministerial meetings tasked the North Atlantic Council in Permanent Session to identify and put together initiatives underway in PfP, including education and training activities such as the PfP Training Centres, the PfP Simulation Network and the Consortium of Defence Academies and Security Studies Institutes, to form a coherent package of measures to reinforce PfP's operational capabilities.

Aim

2. The PfP Training and Education Enhancement Programme (TEEP) will provide a structured approach to optimise and improve training and education in the Partnership. Its principal aim is to increase the ability of training and education efforts to meet current and future demands of an enhanced and more operational Partnership, focussing specifically on the achievement of interoperability. It also seeks to promote greater cooperation and dialogue among the wider defence and security communities in NATO and Partner nations.

Importance of Training and Education in the Partnership

3. As underscored in recent Ministerial meetings there is an awareness that training and education of individuals capable of responding to the challenges of the enhanced and more operational Partnership will be vital for the continued success of the Partnership. In line with the overarching aims of the 1997 SLG Report and subsequent taskings, PfP is assuming a more operational character with greater requirement for interoperability. As PfP cooperation deepens and contains more operational elements, including more robust and sophisticated exercises, demands on qualified human resources have been increasing. This is further complicated by the 
growing challenge of multinationality at lower levels of command and force structures.

\section{Current Experience}

4. Presently, there is a wealth of training and education opportunities throughout the Partnership based on NATO-sponsored activities, including exercises and NATO Schools, and nationally sponsored activities. Notwithstanding these opportunities, exchanges of national experiences and views at NATO fora, including on the IFOR/SFOR and lessons learned from NATO/PfP exercises, have highlighted a number of continuing shortfalls within the area of interoperability. Experience also shows that there are varying levels of interoperability within Partner nations and different needs to be addressed. If not addressed, these challenges will likely impact on the ability to meet the demands of an enhanced and more operational PfP, including the ability of Partner forces to operate together with those of the Allies in NATO-led PfP operations. Training and education will play a key role in addressing such challenges.

\section{Overall Approach}

5. To take full advantage of the education and training contributions by NATO and Nations to the Partnership, the TEEP seeks to optimise and harmonise NATO and national PfP activities as appropriate and to increase transparency of activities "in the spirit of PfP," and bring them closer to the PfP NATO process.

6. There is a need to consolidate existing and emerging tools, deepening and improving them where necessary and reinforcing the effectiveness of their contribution to the overall enhanced and more operational Partnership. Without prejudicing the principle that education and training are ultimately national responsibilities, this effort also entails acknowledging multinational cooperation "in the spirit of PfP" as an essential component in taking Partnership to a higher level of cooperation. A basic assumption for this effort is that within the scope of PfP, both Allies and Partners need to concentrate energy and resources, while collecting and sharing lessons learned. One way to accomplish this is to establish PfP Training Centres, where enhanced training and education activities are available to all Allies and Partners. Another is to strengthen existing defence educational institutions by linking them together. A third is to improve training efficiencies by conducting training on a distributed basis, reaching a wider audience at less cost. These and the optimisation of the already existing NATO-sponsored activities are complementary paths that should be taken up in parallel.

\section{Improving NATO's Contribution}

7. Training and education provided by NATO are a central feature of the Partnership Work Programme (PWP). These activities take many forms: individual education at various NATO Schools, NATO-sponsored conferences and workshops, as well as military activities and exercises. Over time, considerable effort has been made to 
develop and improve these training and education activities. The establishment of the NATO Training Group (NTG) within the International Military Staff, the increasing role of the Military Agency for Standardisation (MAS), the newly established NATO Simulation Policy Group (NSPG), and the Education and Training Branch in the Partnership Coordination Cell (PCC) offer new opportunities for continuing this effort which should be explored. In addition, the PWP feedback system, which has recently been made operational, offers promise for assessing the efficiency and effectiveness of training and education activities. Moreover, programme tailoring to ensure activities offered continue to match evolving requirements would be an important result of ongoing work, and in the context of Individual Partnership Programmes, the possibility to assist Partners to develop a national concept for education and training, including through PARP Ministerial Guidance, should be pursued.

\section{Optimising the Contribution of National and "In the Spirit of" PfP Activities}

8. The important contribution of national and "in the spirit of" PfP activities to the overall Partnership has been recognised and fostered from the early days of PfP. This is particularly true in the training and education field where NATO's capabilities are limited. Just as NATO tools can be improved, national efforts could also be enhanced. Better feedback and assessment mechanisms to assist setting priorities, measuring impact of training on the trained personnel, and designing customised activities, as well as bringing the national PfP training and education activities closer to the NATO process, including by increasing transparency, would complement the endeavours of nations to optimise their offerings. Therefore, a major effort to make more effective use of national contributions should be a part of the TEEP.

\section{Capitalising on Recent Initiatives}

9. Recent initiatives such as the Concept for PfP Training Centres, PfP Simulation Network and the Consortium of Defence Academies and Security Studies illustrate the usefulness of multinational cooperation as essential and complementary components in underwriting a collaborative approach to education in PfP.

10. PfP Training Centres are national facilities made available to all PfP countries to enhance training and education activities. Through the Concept for PfP Training Centres the Allies and Partners took a significant step to foster a greater role for national training facilities within the Partnership. The Concept allows for a range of NATO involvement in these Centres, including by providing expert advice and assistance. In accordance with the terms set out in the Concept, several PfP Training Centres have already been designated, ${ }^{1}$ while others are being considered. As more

1 The PfP Training Centre in Ankara, Turkey; Yavoriv training area, Ukraine; Geneva Centre for Security Policy, Switzerland; PfP Training Centre in Bucharest, Romania; PfP Training Centre in Almnas, Sweden. 
facilities join the family of PfP Training Centres, a network of national facilities should emerge as part of a collaborative approach to training and education.

11. The TEEP should seek to realise the full potential of the relationship between designated national training centres and PfP established through the Concept for PfP Training Centres. It should explore, inter alia, possible networking of these Centres including through the utilisation of simulation networks and the consortium model. It should also consider their geographical and functional spread, as appropriate, to avoid duplication of efforts and resources and to attain complementarity and wider reach. In facilitating the way ahead, interaction among these Centres would be developed initially through the Clearing House mechanism.

12. The PfP Consortium of Defence Academies and Security Studies Institutes focuses on civil-military education in national security and strategic-level military planning, and aims at enhancing multinational education through collaborative approaches linking defence practitioners, scholars, and experts into activity-based networks that facilitate information sharing. It may also extend participation in PfP to include universities and non-governmental institutes. The first annual conference in 1998 on "Networking Security Institutions in the Information Age and the Way Ahead for the PfP Consortium" illustrates the important role the Consortium can play in the overall education and training effort.

13. The Consortium's objectives, which might be further defined by its participants, could include: to foster greater academic and educational opportunities within the defence and security community; to encourage high standards for professional military education; to promote cost-effective education through collaborative distance learning and distributed training, such as via the Internet; to expand dialogue, understanding, and cooperation through security-related research in EAPC countries; and to explore complementary relationships with other institutions such as the NATO Defence College.

14. Possibilities that offer Allies and Partners greater involvement in the Consortium include: participating in the staffing of an interim secretariat whose work will be coordinated by the US-German George C. Marshall Center and shared among institutions in the Partnership; hosting of an annual conference with work supported by workshops and sub-committees and augmented by joint security studies research projects; disseminating lessons learned through a journal or other appropriate publication; and periodic reports to the PMSC on Consortium activities.

15. The PfP Simulation Network (SIMNET) focuses on military command and staff training for NATO-led PfP operations. It will be based on the latest developments of the Combined Joint Task Force Concept and should aim to support related concepts. Its approach is to enhance such training through computer assisted technologies and communications that can link national or multinational staffs and remotesite command posts.

16. Allies and Partners can contribute to the SIMNET's further development by participating as "remote sites" in which the Headquarters leadership role could rotate 
among nations as part of PfP command post exercises to improve command and staff procedures employed in NATO-led PfP operations. Ways should be explored to take advantage of the PfP SIMNET initiative's ability to maximise the impact of advanced technology on the development of the enhanced and more operational Partnership. This could include, inter alia, exploring relationships and mutual support among the PfP SIMNET, the NATO Simulation Policy Group (NSPG) and the ACE Command and Staff Training Programme (ACSTP). Extending the reach of NATO's own efforts in this area to Partner nations for joint and combined training for NATO-led PfP operations should also be considered. Finally, PfP SIMNET participants could volunteer, on a rotational basis, to host conferences to further develop these concepts and to provide periodic reports on PfP SIMNET activities to NATO's Political-Military Steering Committee meeting in EAPC format.

\section{Main Aspects of the Work Ahead}

17. The work ahead will address the following areas:

a. Stocktaking:

In consultation with Partners an accurate assessment should be made of the training and education opportunities available to Partners, including activities "in the spirit of PfP," with a view to identifying more precisely the shortcomings and requirements.

b. Exercises:

Exercises are a key element in assessing standards and overall interoperability. Possibilities for further expanding the scope and complexity of exercises should be explored. The study could also investigate the prospects for regular and appropriately sequenced exercises, including Computer-Assisted Exercises (CAX), Command Post Exercises (CPX) and Field Training Exercises (FTX), in relevant PfP Training Centres.

c. Feedback and assessment mechanisms:

It is imperative to have adequate transparency, feedback and lessons-learned mechanisms to accurately determine the continuing benefit of training and education activities. These mechanisms are necessary to tailor future activities to the evolving needs of the Partnership, taking into account Partners' absorption capabilities.

d. Interoperability:

Further work in the field of training and education could be explored with a view to developing common knowledge of concepts, doctrines, procedures and designs to achieve and maintain the most effective level of interoperability.

e. Linkages and collaboration:

Collaboration among training and education institutions, while respecting their national and NATO character, could help improve the quality of the activities offered and promote harmonisation of programmes. At the same time, collaboration could increase regional co-operation, as well as habits and structures of 
mutual assistance. The full potential of the PfP Training Centres, including their possible networking and the development of the Consortium model, will be explored.

f. Distributed training:

The potential of information and remote communication technologies will be brought to bear extensively on the distributed training and education effort. In this regard, existing and other possibilities will be explored with regard to establishing EAPC-wide simulation networks and training programmes in a costeffective way.

g. National Training and Education Strategies:

The need for and possibilities to provide more direct advice to Partner nations in assisting them to develop national strategies for PfP-related education and training will be studied. It should be recognised that PfP countries have different starting points, resources, capabilities, approaches and priorities.

h. Resources:

The study should take account of possible resource implications for steps to be agreed to further improve and optimise training and education in PfP.

\section{Recommendations}

18. Council is invited to agree the following recommendations:

a. task the PMSC to develop political-military advice for the development of specific recommendations on the above issues as needed and report to the NAC by 1 June 1999;

b. task the NMA's and other appropriate NATO bodies based on political-military advice to be developed in accordance with the above tasking, to provide specific recommendations based on a full stocktaking and assessment of the existing opportunities by 1 September 1999;

c. task the PMSC to provide an interim report to the NAC by mid-September 1999;

d. task the PMSC to develop the PfP Training and Education Enhancement Programme, including specific recommendations, as part of the comprehensive report on the overall implementation of the enhanced and more operational PfP, taking into account military advice, in time for the Autumn 1999 Ministerial meetings;

e. task the Senior Resource Board, in consultation with the NMAs, and the Civil Budget Committee - as part of the tasking in paragraph 19.d. of the main body of this report - to provide an affordability assessment of this Programme by the time of the Autumn 1999 Ministerial meetings. 